\title{
Investigation of the Correspondence between Problems Solving Based on Cognitive Psychology Tests and Programming Course Results
}

\author{
http://dx.doi.org/10.3991/ijet.v10i3.4511 \\ J. Katona, T. Ujbanyi and A. Kovari \\ Institute of Information Technology, College of Dunaujvaros, Dunaujvaros, Hungary
}

\begin{abstract}
Nowadays the education of different programming and software development courses is more difficult. Students are not able to learn solutions and techniques that are needed to solve a problem even though their prominent interests and diligence. In cognitive psychology, there are some test procedures which can measure the problem solving ability of a test subject. In engineering education there is no field where problem solving skills are unnecessary, the test procedures of cognitive psychology adumbrate the success of a programming course. The primary aim of this article is to examine the relationship between the test results of the measurement procedure of cognitive psychology and the results of success of programming courses. If there is correlation between the two, the measurement method can be used as a filter in the recruitment process in secondary schools, colleges or universities.
\end{abstract}

Index Terms-Engineering Pedagogy, Cognitive Psychology, Problem solving, PEBL, Programming

\section{INTRODUCTION}

The continuous growth of the volume of material information to be transmitted is comparable to Moore's Law, the experiential observation in the technological development the number of transistors in a dense integrated circuit doubles approximately every 18 months. Integrated circuit in this law can be compared to the Internet and the number of transistors can be compared to the quantity of information. Students who want to learn and are diligent have no ability to process huge quantity of information.

We think one of the reasons of the problem is the curriculum. There is not enough time for repetition, real thinking and deepening our knowledge. Instead of obtaining real and valuable knowledge, memorizing and learning the curriculum by heart is more important. [1] [2] However, the real aim of education should be teaching students how to adopt new situations, find ways to examine possible solutions and solve the problems. The aim of teaching should not focus on how much the students can memorize during a day without understanding the material. Moreover, if someone is able to understand what they learn, they might not be able to deduct the conclusions. [1] [3] [4]

In teaching engineering it is indispensable to assess the skills of the students, which may contribute to high level implementation of planning, executing and testing. If a measurement method was available to assess the problem solving ability of students, it would be easier to decide whether to pay more attention on the quantity of new information or to develop the problem solving ability.

In cognitive psychology, problem solving ability tests are available that are reliable, generally accepted in diagnostics and research. Nowadays some of these measurement procedures have been implemented by the PEBL (The Psychology Experiment Building Language) test environment. [5] [6]

\section{COMPARISON OF SUSCEPTIBLE METHODS FOR ATTENTION EXAMINATION}

Two classes participated in this test. The test was first done in the first class, the control group, but the results were taken into consideration only in evaluation. Considering the results, the problem solving ability was developed in the second class. For carrying out the test, a course in which good problem solving ability is essential was selected. The name of this course is Programming which presents and applies C\# high level object oriented programming language. The test method of problem solving, which was mentioned in the introduction was used to carry out the test. The Tower of Hanoi was carried out and implemented in computer environment. The location of the test was provided by Rudas Economic High School in Dunaujvaros.

\section{A. Examined Persons}

Students of Rudas Economic High School contributed in the examination. The students volunteered for the tests and two classes participated in the research. They were aged between 17 and 18, according to their gender specification there were 31 boys and 9 girls, and regarding their grade specification, 20 students were from eleventh grade and 20 students from twelfth grade when the experiment was carried out.

\section{B. Tower of Hanoi in The Psychology Experiment Building Language}

The Tower of Hanoi is a traditional problem solving or planning task. During the test, you can move disks from the first rod to the last rod, where in each step the subject can only move one disk and cannot put a bigger disk on the smaller one. There are three rods to solve the problem. To solve the task, a minimum number of steps is required. This variable is $x_{\mathrm{n}}$. The task can only be solved recursively 
where there are $n+1$ disks. [7] Since the bottom disk cannot be moved and any of the disks above cannot be either moved to the middle rod. It can be defined as follows:

$$
\begin{gathered}
x_{\mathrm{n}+1}=x_{\mathrm{n}}+1+x_{\mathrm{n}}=2 x_{\mathrm{n}}+1 \\
\Delta x_{\mathrm{n}}=x_{\mathrm{n}}+1 \\
x_{\mathrm{n}}=y 2^{n}-1 \\
x_{\mathrm{n}}=2^{n}-1
\end{gathered}
$$

Based on the above formula if there are 3 disks then 7 steps are necessary to solve the task:

$$
x_{3}=7
$$

The commonly accepted problem solving measuring procedure was implemented in PEBL test environment, therefore, there is no need for an expert in evaluation because the software shows the results for us. [5] [6] [7]

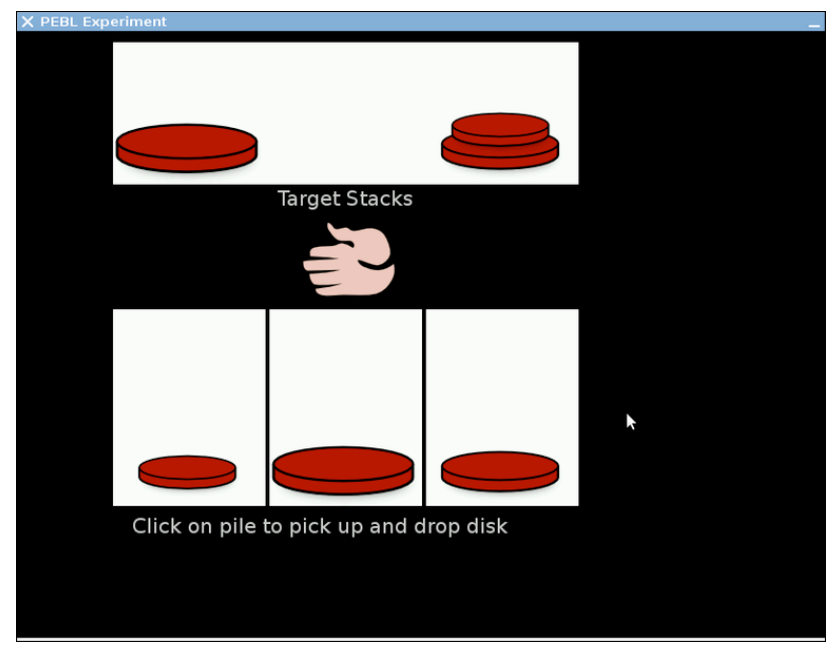

Figure 1. The PEBL's Tower of Hanoi task

\section{Results and interpretation}

Having finished the Tower of Hanoi task, the software evaluates the results immediately and it is available in a report format. Table I shows a TOF test results which were selected randomly from all the results.

TABLE I.

A RANDOM TEST RESULT OF PEBL'S TOWER OF HANOI TASK (TOF)

\begin{tabular}{|c|c|c|c|c|c|c|c|c|c|}
\hline sub & trial & size & current & end & step & $\begin{array}{c}\text { abs- } \\
\text { time }\end{array}$ & $\begin{array}{c}\text { Trial- } \\
\text { time }\end{array}$ & $\begin{array}{c}\text { Click- } \\
\text { time }\end{array}$ & done \\
\hline 2 & 1 & 3 & 236 & 111 & 0 & 6004 & 0 & 0 & 0 \\
\hline 2 & 1 & 3 & 235 & 111 & 1 & 7332 & 1328 & 7332 & 0 \\
\hline 2 & 1 & 3 & 225 & 111 & 2 & 7840 & 1836 & 508 & 0 \\
\hline 2 & 1 & 3 & 224 & 111 & 3 & 8031 & 2027 & 191 & 0 \\
\hline 2 & 1 & 3 & 124 & 111 & 4 & 9192 & 3188 & 1161 & 0 \\
\hline 2 & 1 & 3 & 112 & 111 & 5 & 12301 & 6297 & 3109 & 0 \\
\hline 2 & 1 & 3 & 112 & 111 & 6 & 13564 & 7560 & 1263 & 0 \\
\hline 2 & 1 & 3 & 111 & 111 & 7 & 14877 & 8873 & 1313 & 1 \\
\hline
\end{tabular}

The first column of the table contains the ordinal number of the test subjects, which in this case is the second one. The second column contains the number of attempts. Each student had one turn, so the value did not changed during the execution of the entire test. The third column indicates the amount of disks. This value remained the same the test. The individual disks have a different value compared to final state as shown in the fourth column. For example, neither disks were in their right place in the start. The fifth column illustrates the final state of the solution, which must be achieved by the test subject. The sixth column stores the number of steps required to complete the task, which in this test was 7 , so students had to move 7 disks to achieve the final state. The seventh column shows the absolute time, which illustrates the entire execution time of the task. The examined test subject required 14877 milliseconds to complete the task. The eighth column represents the relative time between the steps which was 1836 milliseconds between the first and second displacements. The ninth column shows the average time to complete the task. The examined test subject required 191 milliseconds between the second and the third steps. The last column represents that whether the executing of the task was finished or not. Value 0 means the test is in process, value 1 means that the test has finished.

Primarily, the required average time, the number of steps, current position of the disks and the final state which are necessary to solve the PEBL's TOH task, to be examined in the psychological research. Because of the easier perspicuity, this article is based on the first two factors, which were mentioned above.

Figure 2 shows results in $\mathrm{TOH}$ test and marks of each students in the test group. The maximum number of steps was 30 , whoever reached this value, was disqualified.

The grade point average (GPA) of the students in the test group at half term was 3.35 , while the average amount of the necessary steps to implement the test was 18.1. The correlation coefficient result, which was provided by TOF test, assumes a strong relationship with the GPA, which was reached by the students at $95 \%$ significance level.

Distribution of students (half-year) - test group

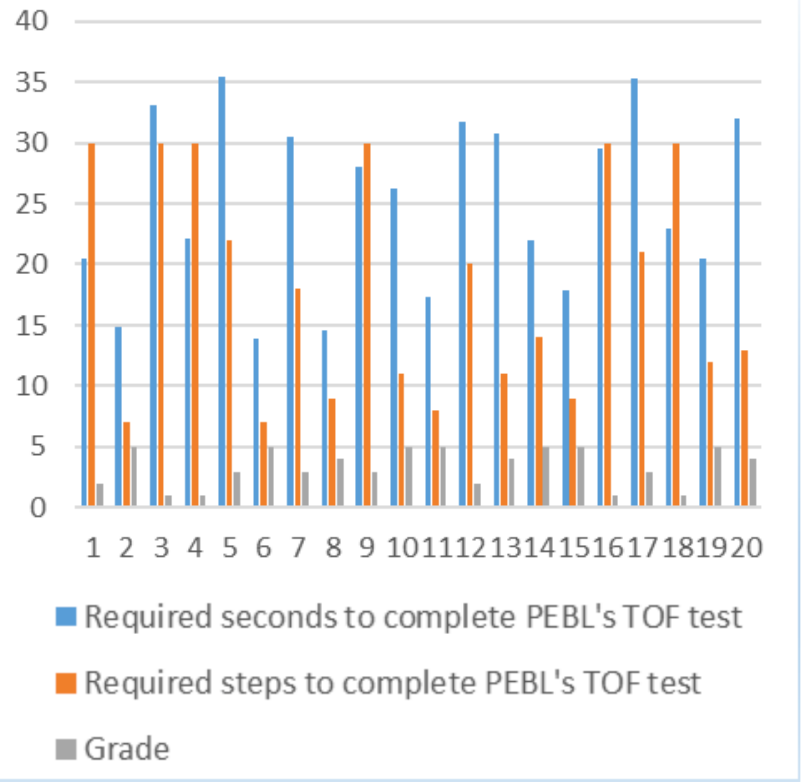

Figure 2. Result of the test group (half-year) 
TABLE II.

RESULTS OF TEST GROUP AT HALF-TERM

\begin{tabular}{|c|c|}
\hline Grade Point Average & 3,35 \\
\hline $\begin{array}{c}\text { Average of required steps to } \\
\text { complete PEBL's TOF test }\end{array}$ & 18,1 \\
\hline Correlation Coefficient & $-91,57 \%$ \\
\hline
\end{tabular}

Based on the observed information during the first half of the year, the emphasis was placed on the development of problem solving skills rather than the transfer of knowledge in the second half. At the end of the school year, the PEBL's TOF test was performed again, the result of which is illustrated in Figure 3.

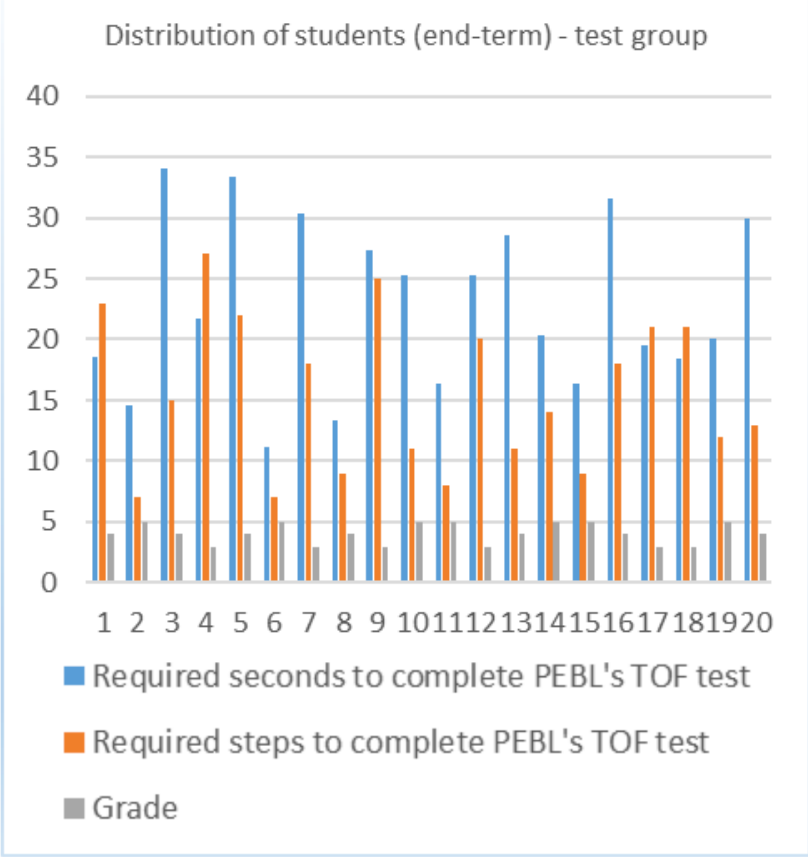

Figure 3. Result of the test group (end-term)

The third figure shows the grades, which were achieved by each student of the test group at the end of the school year. The number of steps that were needed to solve the problem was maximized in 30 pieces too, however, at the end of the school year, every student was able to reach the final state of the test successfully within the specified maximum number of steps, which shows improvement compared to the test carried out at the beginning of the school year.

The GPA of the test group was 4.05 at end term, while the average amount of necessary steps to effectuate a successfully test was 15.5 units. The correlation coefficient result, which was provided by TOF test, assumes a strong relationship with the GPA, which was attained by the students at $95 \%$ significance level.

TABLE III.

RESULTS OF TEST GROUP AT END-TERM

\begin{tabular}{|c|c|}
\hline Grade Point Average & 4,05 \\
\hline $\begin{array}{c}\text { Average of required steps to } \\
\text { complete PEBL's TOF test }\end{array}$ & 15,5 \\
\hline Correlation Coefficient & $-80,14 \%$ \\
\hline
\end{tabular}

Distribution of students (half-term) - control group

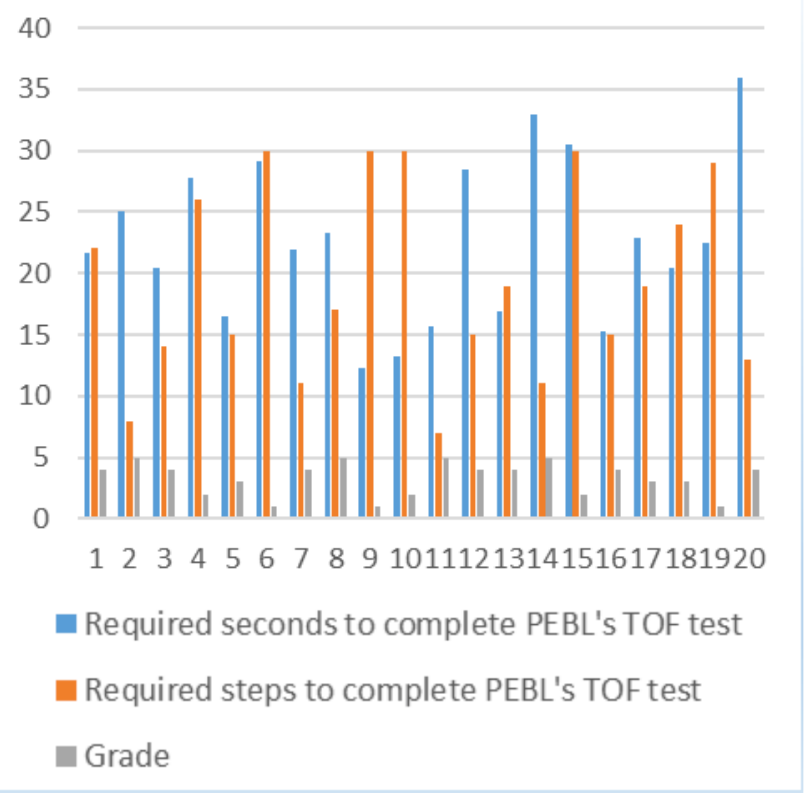

Figure 4. Result of the control group (half-term)

The fourth figure shows the results of the PEBL's TOH test and the grade which were achieved by the control group. The maximum number of steps was maximized in 30 steps, if this amount was reached, the test was considered unsuccessful.

TABLE IV.

RESULTS OF CONTROL GROUP AT HALF-TERM

\begin{tabular}{|c|c|}
\hline Grade Point Average & 3,3 \\
\hline $\begin{array}{c}\text { Average of required steps to } \\
\text { complete PEBL's TOF test }\end{array}$ & 19,25 \\
\hline Correlation Coefficient & $-89,58 \%$ \\
\hline
\end{tabular}

The GPA of the test group at half-term was 3.3, while the average amount of the necessary steps to implement the test was 19.25. The correlation coefficient result, which was provided by TOF test, assumes a strong relationship with the GPA, which was reached by the students at $95 \%$ significance level.

The fifth figure shows the grades, which were achieved by each student of the control group at the end of the school year. The number of steps that were needed to solve the problem was maximized in 30 steps. If this amount was reached, the test was considered unsuccessful.

The GPA of the control group was 3.15 at end-term, while the average amount of necessary steps to effectuate a successfully test was 19 units. The correlation coefficient result, which was provided by TOF test, assumes a strong relationship with GPA, which was attained by the students at $95 \%$ significance level. 


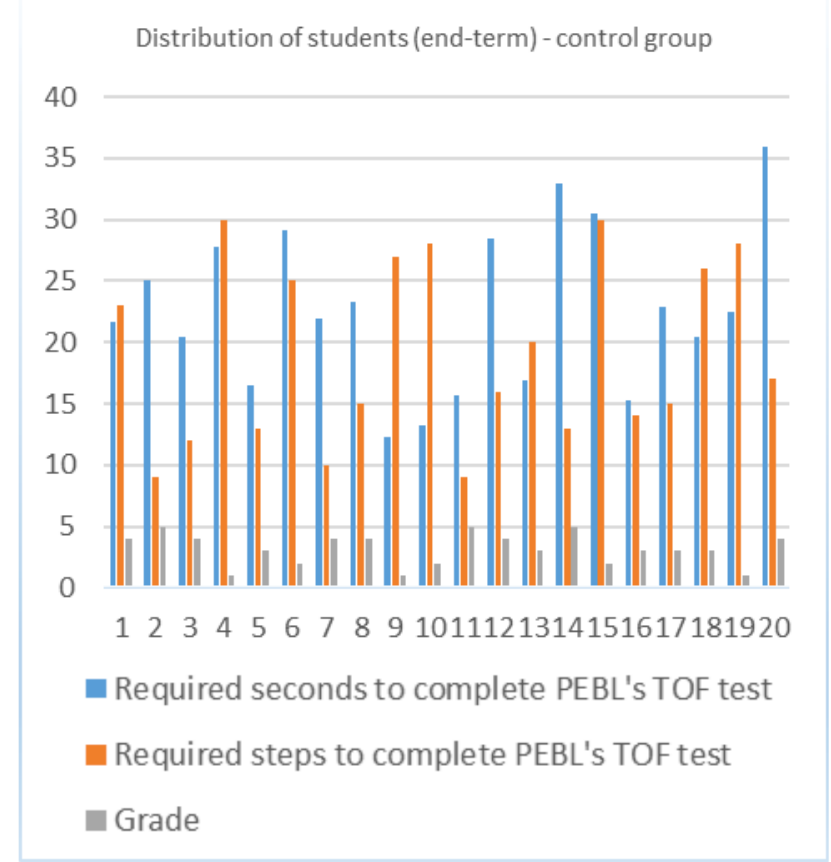

Figure 5. Result of the control group (end-term)

TABLE V.

RESULTS OF CONTROL GROUP AT HALF-TERM

\begin{tabular}{|c|c|}
\hline Grade Point Average & 3,15 \\
\hline $\begin{array}{c}\text { Average of required steps to } \\
\text { complete PEBL's TOF test }\end{array}$ & 19 \\
\hline Correlation Coefficient & $-84,16 \%$ \\
\hline
\end{tabular}

\section{CONCLUSION}

The article provides a comprehensive analysis about whether the development of students' problem solving ability contributes to improve the grades of engineering subjects. In this research one engineering subject, Programming, was examined since this subject requires excellent problem solving ability. In addition, the PEBL's TOF test, which is able to measure problem solving skills and is commonly used and accepted by cognitive psychology was used to investigate the relationship between the grades of Programming subject and the problem solving skill. The research demonstrates that there is a strong relationship between the result of the PEBL's HOF test and the obtained grades. Two groups' results were compared during the research. In the first group, the problem solving skills developed in the second half of the school year within the framework of the Programming subject.

The problem solving skills centered education demonstrates that the results, which were achieved at the end of the school year improved by 0.7 marks, moreover, the PEBL's TOF test results also significantly improved in the test group, while in the control group, wherein the pri- marily knowledge transfer education was conducted according to the syllabus, the difference was not detected. The research illustrates that the PEBL's TOF test results may show a prediction about the effectiveness of education in case of an engineering subject and it can be used in the recruitment process method to forecast the expected success of prospective students.

\section{REFERENCES}

[1] Yang, C.C.; Chen, Hsinchun; Honga, Kay (2003). Visualization of large category map for Internet browsing. Decision Support Systems 35 (1): $89-102 . \quad$ http://dx.doi.org/10.1016/S01679236(02)00101-X

[2] Speier, Cheri; Valacich, Joseph. Vessey, Iris (1999). The Influence of Task Interruption on Individual Decision Making: An Information Overload Perspective. Decision Sciences 30. http://dx.doi.org/10.1111/j.1540-5915.1999.tb01613.x

[3] Hemp, P. (2009). Death by information overload. Harvard Business Review, 87(9), 83-89.

[4] Cheng, R \& Vassileva (2006). Design and Evaluation of an adoptive incentive mechanism for sustained educational online communities, User modeling and user-adapted interaction. Dordrecht. 16(3-4), p. 321.

[5] Piper, B. J., Li, V., Eiwaz, M. A., Kobel, Y. V., Benice, T. S., Chu, A. M., Olson, R., Rice, D., Gray, H., Mueller, S. T., \& Raber, J. (2012). Executive function on the psychology experiment building language tests. Behavior research methods, 44(1), 110123. http://dx.doi.org/10.3758/s13428-011-0096-6

[6] Mueller, S. T. (2010). A partial implementation of the BICA cognitive decathlon using the Psychology Experiment Building Language (PEBL). International Journal of Machine Consciousness 2 (2): 273-288. $\quad$ http://dx.doi.org/10.1142/S179384 $\underline{3010000497}$

[7] Kotovsky, K., Hayes, J. R., \& Simon, H. A. (1985). Why are some problems hard? Evidence from Tower of Hanoi. Cognitive Psychology, 17(2), 248-294. $\quad$ http://dx.doi.org/10.1016/0010$\underline{0285(85) 90009-\mathrm{X}}$

\section{AUTHORS}

J. Katona works as a teacher of engineering specialization of IT at College of Dunaujvaros. His research areas include engineering pedagogy and psychology, bioinformatics, cognitive psychology and software development. College of Dunaujvaros, Dunaujvaros, Hungary (e-mail: katonaj@mail.duf.hu).

T. Ujbanyi works as a teacher of engineering specialization of IT at College of Dunaujvaros. His research areas include engineering pedagogy and psychology, IT security and social engineering, information and communications technology. College of Dunaujvaros, Dunaujvaros, Hungary (e-mail: ujbanyit@mail.duf.hu).

A. Kovari works as associate professor at College of Dunaujvaros. He received the $\mathrm{PhD}$ degree from the University of Pannonia, Hungary. His main research fields include IT, bioinformatics, control theory and mechatronics. College of Dunaujvaros, Dunaujvaros, Hungary (email: kovari@mail.duf.hu).

Submitted 08 March 2015. Published as resubmitted by the authors 11 May 2015. 